\title{
Construction and implementation of a low-cost electronic experiment control interface
}

\author{
J. A. D'ANDREA and J. KNEPTON \\ Naval Aerospace Medical Research Laboratory, Pensacola, Florida
}

\begin{abstract}
Low-cost electronic experiment control boards (ECBs), developed by Walter and Palya (1984), were constructed and implemented for use at the Naval Aerospace Medical Research Laboratory. Each ECB was wired to control experiments using animals as subjects. The ECBs have been connected to IBM-compatible microcomputers and serve essentially as intelligent interfaces between the subject and the microcomputer. Relative advantages and disadvantages of the control board, including construction and programming techniques, as well as cost, are discussed.
\end{abstract}

As research funding dwindles, justifying the use of expensive minicomputers and microcomputers to control simple experiments becomes more difficult. As Walter and Palya (1984) pointed out, the best approach is to use the laboratory mini- or microcomputer for tasks such as database management, data analysis, and graphics presentations and to use an inexpensive experiment control board (ECB) to arrange the contingencies of an experiment and store the resulting data. With the two systems interconnected, the experiment can be controlled inexpensively by the ECB, and the more extensive resources of the minicomputer or microcomputer can be used for data storage, analysis, and graphic representation. If one lab computer is interconnected to several ECBs, then a cost-effective laboratory system can be achieved.

At the Naval Aerospace Medical Research Laboratory (NAMRL), such a system has been implemented. The purpose of this paper is to disseminate information about the assembly, setup, and operation of this laboratory computer system, as well as to reveal the advantages and disadvantages of this approach.

\section{Construction of the Experiment Control Computer}

Procurement of the electronic circuit board (D \& D Electronics, Inc., 5175 Moores Mill Road, Huntsville, AL 35811) and the electronic circuit board components was the most time-consuming aspect of the project. The electronic components were not all available from a single vendor, and, in some cases, extensive searching of

\footnotetext{
Trade names of materials and/or products of commercial or nongovernment organizations are cited as needed for precision. These citations do not constitute official endorsement or approval of the use of such commercial materials and/or products.

Opinions and conclusions contained in this report are those of the authors and do not necessarily reflect the views or the endorsement of the Navy Department. This research was supported by the Naval Medical Research and Development Command under work unit number 62233N MM33130.002-7001, Accession No. DN277077. Address correspondence to the authors at the Naval Aerospace Medical Research Laboratory, Naval Air Station, Pensacola, FL 32508.
}

catalogs and several phone calls were required to identify the correct components. This task was simplified by the loan of a working ECB from W. L. Palya.

Once the various components were received, the actual assembly time for each ECB was rapid, averaging about $30 \mathrm{~h}$ each by the second author, who is a research physiologist and not an experienced electronics technician. An excellent guide for assembly and operation of the ECB is available (Walter \& Palya, 1986).

\section{Debugging of the Experiment Control Computer}

After assembly and extensive checking for correct component installation, power-up was attempted. In all cases, the ECBs either did not operate or operated improperly on the initial test. In some cases, components were not properly soldered, but, after careful checking, a short circuit was discovered on most of the etched circuit boards, which prevented proper operation of the dynamic memory circuits on the board. The etched data lines on the circuit board are extremely fine and were, in most cases, touching adjacent lines. After the errors on the memory data lines were carefully scratched away, the ECBs operated properly. On subsequent versions of the printed circuit board, this problem was corrected (personal communication, W. L. Palya, January, 1987). Each ECB was mounted in a steel cabinet $(17.4 \times 14 \times 8.5$ in. $)$ for protection and to prevent radio-frequency interference of the microprocessor from other "noisy" laboratory equipment. Interconnection plugs for the serial RS-232 port, data input and output lines, and the audiocassette tape recorder were mounted on the back of the steel cabinet.

Connection of the ECB to an experimental setup and the host microcomputer was simplified by using D-type connectors, but soldering the 25 pin and the 37 pin connectors was tedious. Use of the connecting plugs, however, made it a simple task to remove and replace an ECB from an experimental setup when necessary. The alternative was to "hard wire" each ECB to an experimental setup, which would have been much more tedious and time-consuming should replacement of the ECB become necessary. 


\section{Implementation of the Experiment Control Computer}

As described by Walter and Palya (1984), the ECB uses a 6809 microprocessor with 16K of dynamic memory and 16K of PROM memory. The dynamic memory is used to store operating programs, as well as data collected during the experiment. More recent versions of the ECB have an expanded dynamic memory of $64 \mathrm{~K}$. The PROM memory is used to provide permanent read-only memory for the system operating software. Different versions of the ECB are available, all of which use the same printed circuit board. The ECBs differ only in the data stored in the PROM. A simple stand-alone version uses a form of BASIC language (ECBASIC) to operate the ECB and automatically performs such functions as input-output and timing. This version was designed to operate with a video display terminal, a printer, and an audiocassette tape. A second version utilizes ECBASIC and operates under a networking arrangement with the serial RS-232 communications protocol. This allows a single host computer to communicate with several ECBs linked together by a common RS-232 communications wire. A third version of the ECB utilizes a completely different operating system, the experiment control language, which uses precompiled control code that allows the ECB to make precise elapsed timing (down to $1 \mathrm{msec}$ ) for the measurement of interevent times. Other versions of the ECB, as well as additional details on the versions described above, can be found in Walter and Palya's (1984) paper.

At NAMRL, the ECBASIC stand-alone version has been implemented. Instead of a video terminal, a host microcomputer was set up using the serial RS-232 link to download programs and collect data from the ECB. This approach was taken because only one experimental setup was needed to conduct a particular research program. It was not necessary to implement the networking version of the board when only a single ECB was linked to the microcomputer. There was still a distinct advantage, however, in that during the time the ECB was conducting the experiment and collecting data, the host microcomputer was free to perform other functions such as data reduction, graphical analysis, and statistical analysis of previously gathered data. Using the host microcomputer to directly conduct the experiment in place of the ECB would not have allowed the other functions mentioned above to be performed simultaneously.

\section{Communication Software}

A variety of software packages designed for communication with a remote device are available. At NAMRL, the communications program CROSSTALK has been successfully used for the host microcomputer to communicate with the ECB via the serial RS-232 communications line. As described above, the host microcomputer has served in place of the video display terminal. Control programs written on the host microcomputer with a line editor or word processing package are downloaded to the
ECB and then given a "run" command. While the ECB is conducting the experiment, the experimenter can use the microcomputer for other purposes. When the experiment is completed, the data are listed by the ECBASIC control program and collected (via serial RS-232 link) by the host microcomputer for printing or for storage on floppy disk.

\section{Programming the Experiment \\ Control Computer}

The ECBASIC language commands and arithmetic operators are described in detail in Walter and Palya's (1986) documentation, which is available from W. L. Palya, Jacksonville State University, Jacksonville, AL 36265. This manual is very well written and easily understood by anyone familiar with the BASIC language. In this laboratory, simple (fixed interval) to complex (chain random ratio continuous reinforcement with a limited hold) contingencies have been successfully programmed on the ECB. In most cases, the measurement of elapsed time has been acceptable. For example, reaction times in the range of 300-700 msec have been accurately measured and verified as correct (within $10 \mathrm{msec}$ ) by a storage oscilloscope.

\section{Advantages and Disadvantages of the Experiment Control Computer}

The primary advantage of the ECB is the low cost. For the revision $\mathrm{D}$ circuit baord, which uses miniature relays on the output lines, the cost was approximately $\$ 475$, which included the power supply and a metal cabinet to house the ECB. A second advantage is the stand-alone feature. A minicomputer or microcomputer is not needed. With a simple video terminal, experiments can be conducted using the experiment control computer. Actually, we may not have even needed the video terminal. Control programs that are run often can be loaded onto the PROM for immediate use each time the computer is turned on. A dot matrix printer is necessary to produce a hard copy of the collected data. Downloading of programs from a host computer or through the audiocassette interface is not required if the programs are permanently stored on the PROM memory. The ability to interface with a host microcomputer, such as the IBM PC or any computer that has a serial interface, is the third advantage. A network of ECBs connected to one host computer is an effective and cost-efficient way to simultaneously conduct many experiments. A fourth advantage is the assembly and programming manual (Walter \& Palya, 1986), which is informative and clearly explains the assembly and opertion of the ECB. The section on ECBASIC is well written and details the different commands that are available in this language.

The only disadvantage has been susceptibility to electromagnetic interference (EMI). Occasionally, the ECB has failed to complete a program when devices such as electric drills, which produce some EMI, have been used in the laboratory. A variety of methods can be used to 
reduce the EMI problem, but the failure rate has been so infrequent that these have not been pursued at this laboratory.

\section{Conclusions}

The ECB developed by Walter and Palya (1984) has proven to be a cost-effective approach to conducting many experiments. The system, comprised of a host computer networked with several ECBs, can perform the functions required of a large minicomputer at a fraction of the cost. Assembly and implementation of the ECBs was accom- plished with only a few problems, and the performance of a host microcomputer and an ECB has been excellent.

\section{REFERENCES}

Walter, D. E., \& PALyA, W. L. (1984). An inexpensive experiment controller for stand-alone applications or distributed processing networks. Behavior Research Methods, Instruments, \& Computers, 16, 125-134.

Walter, D. E., \& Palya, W. L. (1986). Document set for experiment controller. Jacksonville, AL: Jacksonville State University, Department of Psychology. 